Article

\title{
Anomalous Features of Water Vapor Transport during Severe Summer and Early Fall Droughts in Southwest China
}

\author{
Zhenchen Liu ${ }^{1}$, Guihua Lu ${ }^{1}$, Hai He ${ }^{1, *}$, Zhiyong $\mathrm{Wu}^{1}$ and Jian $\mathrm{He}^{2}$ \\ 1 College of Hydrology and Water Resources, Hohai University, Nanjing 210098, China; \\ lzc90_hhu@139.com (Z.L.); lugh@hhu.edu.cn (G.L.); wzyhhu@gmail.com (Z.W.) \\ 2 Hydrology and Water Resources Investigation Bureau of Jiangsu Province, Nanjing 210029, China; \\ longlivehj@hotmail.com \\ * Correspondence: hehai_hhu@hhu.edu.cn; Tel.: +86-25-8378-7481
}

Academic Editors: Paulo Barbosa and Arjen Y. Hoekstra

Received: 27 November 2016; Accepted: 29 March 2017; Published: 31 March 2017

\begin{abstract}
Water vapor transport (WVT) is an important element in drought development. In this study, we examined the geographical and vertical anomalies of WVT during severe summer and early fall drought processes and their occurrence, persistence and recovery phases in Southwest China (SWC) by using the method of standardized anomalies (SA) and composite analysis. The SA-based indices of WVT were built up to quantify composited anomalous WVT channels objectively. Essentially, we further explored the synchronous and lagged correlations between drought processes and these channels. Key points and limitations include: (1) Two drought-related WVT channels were geographically identified with composited SA below -0.2 , based on the composite of severe drought processes. The Somali channel is characterized by zonally less-than-normal African-Asian continental WVT anomalies originating from Somalia, whereas the IndoChina-Peninsula channel represents meridionally less-than-normal WVT anomalies from the IndoChina-Peninsula; (2) Both geographical and vertical WVT anomalies were intensified and concentrated at the time of drought occurrence, and then weakened and became scattered at drought recovery; (3) Most drought-related WVT anomalies were distinguishable from those of wetter events; (4) The IndoChina-Peninsula channel performs better in correlations with these drought and wetter processes than the Somali channel. Therefore, dynamic and thermodynamic anomalies need to be investigated, which are important for exploring the drought mechanism.
\end{abstract}

Keywords: water vapor transport; standardized anomalies; drought processes; Southwest China

\section{Introduction}

During the past 10 years, Southwest China (SWC), including Yunnan, Guizhou, Guangxi, Sichuan, and Chongqing, experienced severe socioeconomic losses owing to severe droughts. For example, during the severe drought from autumn 2009 to spring 2010, approximately 21 million people suffered from a shortage of drinking water, and economic losses reached nearly US $\$ 30$ billion [1]. Because of the significance of these drought events, much attention has been paid to atmospheric circulation and tele-connection patterns pertaining to drought in SWC. Most of these studies have focused on particular events such as severe droughts that occurred in summer 2006, autumn 2009 to spring 2010, and summer 2011 [2]. For the summer droughts in 2006 and 2011, the Western Pacific subtropical high [3-5], which stretched westward in 2006 but withdrew eastward in 2011, is one of the most important factors [5]. The South Asia High also maintained a position more northward than normal during these two summer droughts [3,5]. For the 2009-2010 drought, remote forcing that may affect regional 
thermodynamic characteristics, such as North Atlantic Oscillation (NAO) [6,7], Arctic Oscillation (AO) $[1,8,9]$, and El Niño-Southern Oscillation (ENSO) [1,9,10], have gained great attention. The AO index amounted to the lowest value in the 2009-2010 winter recorded since the mid-20th century, resulting in an eastward track of cold waves with a coincident reduced northerly flow of cold air into SWC $[1,8,9]$, as summarized by Wang et al. [2]. Moreover, a previous El Niño Modoki occurrence is an important external forcing that shaped the anomalous East Asian circulation pattern $[1,9,10]$, which finally induced a strong decline in water vapor transport to SWC in the 2009-2010 drought. A negative-phase NAO generates insufficient precipitation over SWC in dry seasons [6,7]. A schematic map of the large-scale atmospheric patterns associated with these droughts in SWC, as shown in Figure $1 b$, was originally produced by Wang et al. [2].
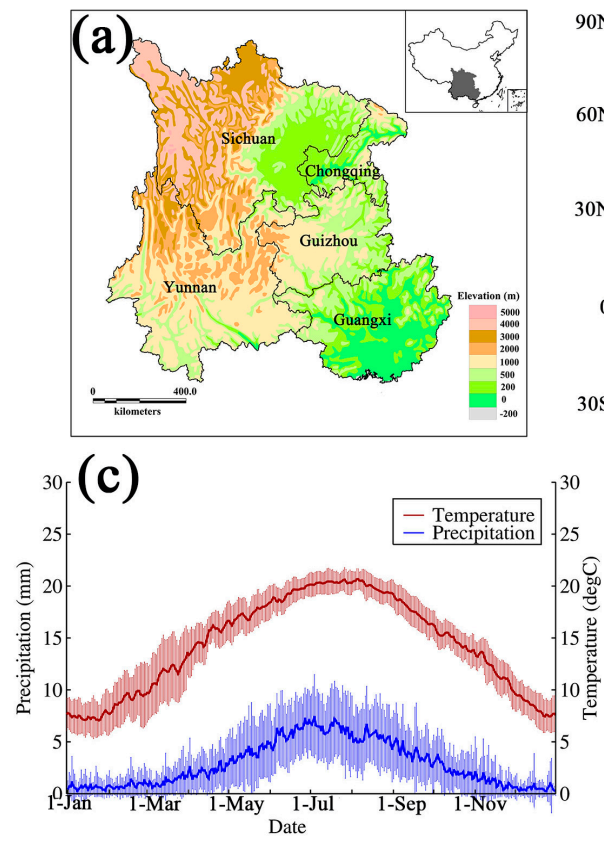
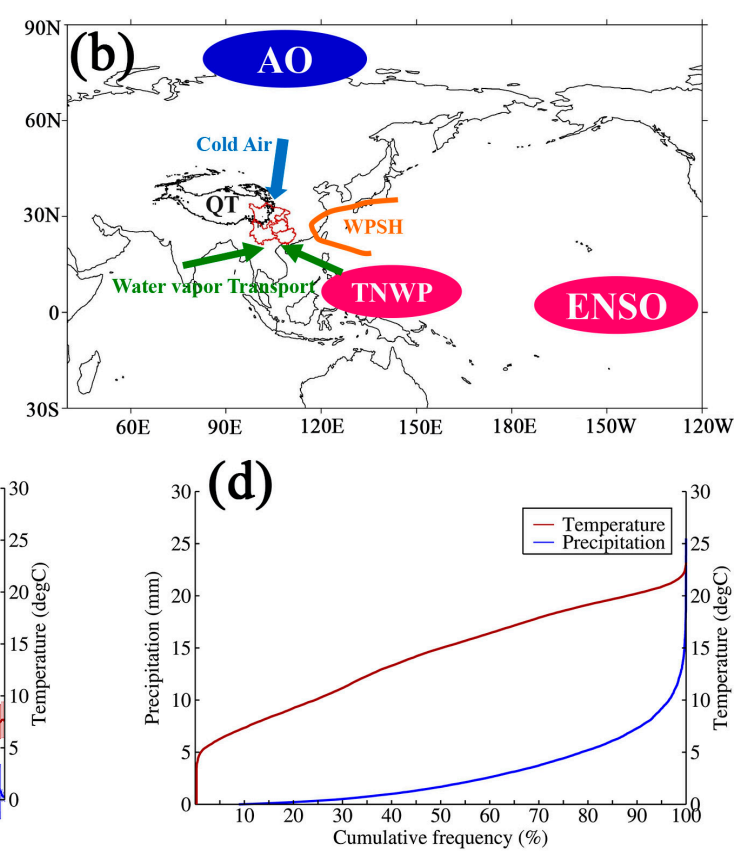

Figure 1. (a) Topography of Southwest China (SWC) and its geographic location in China (top right). (b) Schematic diagram of the influential atmospheric factors related to droughts in SWC [2]. TNWP, ENSO, WPSH, AO and QT stand for the tropical Northwest Pacific, El Niño Southern Oscillation, Western Pacific Subtropical High, Arctic Oscillation, and the Qinghai-Tibet Plateau, respectively. (c) Temporal evolution of mean daily observed precipitation and temperature (1979-2014) averaged over SWC. Thick lines represent daily values, while light shadows stands for one standard deviation. (d) Cumulative frequency distribution of all daily precipitation and temperature (1979-2014) averaged over SWC.

Aside from considerable discussions on the aforementioned large-scale circulation and tele-connection patterns, only a few studies have been conducted on anomalous WVT during droughts in SWC. For example, meridional WVT over the Bay of Bengal (BOB) and the South China Sea (SCS) decreased in the 2009-2010 drought, which might be related to abnormal changes in the tropical sea surface temperature (SST) [11]. The anomalous anti-cyclonic and cyclonic circulations over these regions are also partly responsible for it [12]. During the 2006 summer drought, anomalous WVT from northeast to southwest indicated a negative abnormal belt of meridional WVT from the IndoChina-Peninsula to the Sichuan-Chongqing region [3,13]. Similarly, weak northward WVT from the BOB contributed to the 2011 summer drought [14].

In general, anomalous WVT contributed greatly in these case studies of three severe drought events. However, the following questions remain: What are the common characteristics of severe droughts? What are WVT anomalies associated with the temporal evolution of the entire drought process and its 
occurrence, persistence and recovery phases? Are these anomalous features during the entire process and its phases distinguishable from those of wetter events? Do WVT anomalies have a close relationship with the development of drought process? To answer these scientific questions, we focused on WVT anomalies during the entire processes and different relevant phases.

Because WVT toward SWC over the sea prevails in summers and brings adequate water vapor, no severe drought occurrence is expected. However, devastating and severe droughts such as those occurring in the summers of 2006 and 2011 actually occurred. In addition, some summer droughts are closely related to the occurrence of droughts in the following autumns and winters. For example, precipitation deficits have appeared in the previous summer before the 2009-2010 drought $[1,8]$. Therefore, the focus of the present study is severe summer drought in SWC. Because the recognized 2006 and 2011 severe summer droughts actually ended in the autumn, summer, and early fall, drought and wetter processes that began between 1 June and 31 August and ended between 31 August and 10 October were selected for study.

The objectives of this study are to: (1) identify severe summer and early fall drought events and obtain their temporal characteristics; (2) comprehensively investigate anomalous geographical features of vertically integrated WVT and that at different boundaries during the entire processes and different phases; (3) investigate whether the identified anomalous features are distinguishable from those of wetter processes; and (4) build relevant indices to quantify geographical WVT anomalies, in order to explore the synchronous and previous correlation of vertically integrated WVT anomalies and temporal evolution of the drought processes.

\section{Materials and Methods}

\subsection{Data and Studying Area}

Three sets of data products were used in this study. The first is the second version Datasets of Observed Daily Precipitation Amounts and Temperature at each $0.5^{\circ} \times 0.5^{\circ}$ grid point in China during 1979-2014, which were kindly provided by the Climate Data Centre of the National Meteorological Information Centre, China Meteorological Administration. In addition, 503 gridded points were used to calculate the area-averaged daily precipitation and temperature in SWC. These datasets were kindly provided by the Climate Data Centre of the National Meteorological Information Centre, China Meteorological Administration.

Second, the National Centers for Environmental Prediction (NCEP)-Department of Energy (DOE) Reanalysis II (R2) data products were used, which is an improved version of the NCEP Reanalysis I (R1) model with corrected errors and updated parameterizations of the physical processes [15]. The global dataset of $\mathrm{R} 2$ has a resolution of $2.5^{\circ} \times 2.5^{\circ}$ at 17 pressure levels extending from 1979 to 2014 . The R2 data products for relative humidity, air temperature, and $\mathrm{u}$ and $\mathrm{v}$ components of the wind were used in water-vapor-related calculation.

Additionally, the ERA-Interim re-analysis datasets [16], provided by the European Center for Medium-Range Weather Forecasts (ECMWF), were used for comparison of spatial resolution in the WVT calculation. The ERA-Interim data products for specific humidity, $u, v$, divergence, and the vertical integral of northward and eastward water vapor flux were retrieved from 23 pressure levels between $300 \mathrm{hPa}$ and $1000 \mathrm{hPa}$. ERA-Interim re-analysis products have a spatial resolution of $0.75^{\circ} \times 0.75^{\circ}$ and 6-h temporal resolution extending from 1979 to 2014 .

Southwest China (SWC) covers an area of approximately 1.23 million $\mathrm{km}^{2}$, accounting for $12.9 \%$ of the country. Its latitude and longitude ranges vary from $22^{\circ} \mathrm{N}$ to $32^{\circ} \mathrm{N}$ and $98^{\circ} \mathrm{E}$ to $110^{\circ} \mathrm{E}$, respectively. This region comprises four provinces (Sichuan, Guizhou, Yunnan and Guangxi) and one municipality (Chongqing) [2]. The elevation of SWC consistently decreases from northwest to southeast (Figure 1a), including parts of the Qinghai-Tibet Plateau, plains, and basins. Despite the complex terrain, the influence of various elevations on the aforementioned precipitation and temperature datasets has been eliminated as much as possible. Both mean daily precipitation and temperature 
(1979-2014) for SWC (Figure 1c) reach maximum values in July. Summer and early fall (June-October) precipitation amounts accounts for more than $70 \%$ of the total precipitation. As shown in Figure $1 \mathrm{~d}$, the 25th-75th percentiles of daily precipitation and temperature range from $0.3 \mathrm{~mm}$ to $4.4 \mathrm{~mm}$ and from $10.2{ }^{\circ} \mathrm{C}$ to $18.6^{\circ} \mathrm{C}$, respectively. Figure $1 \mathrm{~b}$, cited from the literature review produced by Wang et al. [2], summarizes the factors currently recognized as possible influences in the drought formation over SWC. Essentially, water vapor transported from the ocean is one of the important factors responsible for droughts in SWC.

\subsection{Using SPI1 (One-Month Standardized Precipitation Index) to Capture Severe Summer and Early Fall Drought and Wetter Events}

Because precipitation and evapotranspiration are important factors governing the local water balance, it is necessary to investigate which drought index, such as the Standardized Precipitation Index (SPI) [17] and the Standardized Precipitation Evaporation Index (SPEI) [18], is a better selection for meteorological drought in SWC. We compared the temporal evolution of SPI and SPEI in particular grid points in SWC. The results showed that the temporal evolution of these two drought indices was quite similar in this region. Since SPEI calculation needs additional temperature data sets and is relatively complex, the SPI was eventually used in the present study.

The Standardized Precipitation Index (SPI) was first presented by Mckee et al. [17], based on the probability of the long-term precipitation record at any flexible time scale. It is used by national meteorological and hydrological services to characterize meteorological droughts [19]. SPI at different timescales corresponds to different drought types, such as 1-2-month SPI for meteorological drought, 1-6-month SPI for agricultural drought, and 6-24-month SPI or more for hydrological drought analyses and applications [19]. In this study, the one-month SPI (SPI1) was chosen because we focused on WVT, which is closely related to meteorological drought. To analyze the WVT conditions during different drought phases, we attempted to determine precise dates of occurrence, persistence, and recovery phases according to the daily drought index. However, SPI1 is generally computed for monthly precipitation aggregated at a one-month scale. Therefore, we employed a method recommended by the World Meteorological Organization (WMO) [19] to update SPI1 every day, on the basis of a daily running window of 31 days rather than monthly precipitation aggregated at one month. For example, SPI1 on 2 February 1999, was calculated by using the cumulative precipitation amount from 3 January to 2 February 1999, and was compared with contemporary historical records of 1979-2014.

To better understand drought-related WVT anomalies, we compared these values with those of wetter events. We recognized both drought and wetter processes with the complete time series of SPI1 from 1979 to 2014. The index, which is used to identify drought and wetter processes, is based on area-averaged rainfall in SWC. Similar to the rules of SPI grade division recommended by $\mathrm{WMO}$, we also used the division rules shown in Table 1, to identify drought and wetter events with different grades.

Table 1. Drought and wetter process classification according to SPI1 (one-month Standardized Precipitation Index) values.

\begin{tabular}{cccc}
\hline Class & Value & Class & Value \\
\hline extremely wet & 2.00 and more & slightly dry & -0.99 to -0.50 \\
very wet & 1.50 to 1.99 & moderately dry & -1.49 to -1.00 \\
moderately wet & 1.00 to 1.49 & severely dry & -1.99 to -1.50 \\
slightly wet & 0.50 to 0.99 & extremely dry & -2.00 and less \\
near normal & -0.49 to 0.49 & & \\
\hline
\end{tabular}

We selected summer and early fall drought and wetter processes that began between 1 June and 31 August and ended between 31 August and 10 October. The drought (wetter) events were identified when SPI1 was below -0.50 (above +0.50 ) for at least 30 consecutive days. According to the rules 
in Table 1, each daily value of the recognized time series was assigned to the corresponding SPI1 grade (i.e., severely dry). Starting from the most severe grade, we calculated the ratio of days with a particular grade accounting for the total days of the entire process. When the ratio increased beyond $30 \%$, the corresponding grade was assigned to the entire drought or wetter process. For example, as shown in Figure 2, the proportion of the severely dry days was beyond 30\%. Accordingly, the 2006 summer drought corresponded to the severe grade. Essentially, we identified drought and wetter events with different severity grades, such as extreme, severe, moderate, and slight. In this study, we focused on extreme and severe drought and wetter processes in the summer and early fall seasons. To specify their seasonality, the following criteria were used: If the most severe grade of drought or wetter process occurred in the summer or early fall, we identified it as the summer or early fall drought or wetter process. If the most severe grades appeared in both summer and early fall, the term "summer-fall" was used.

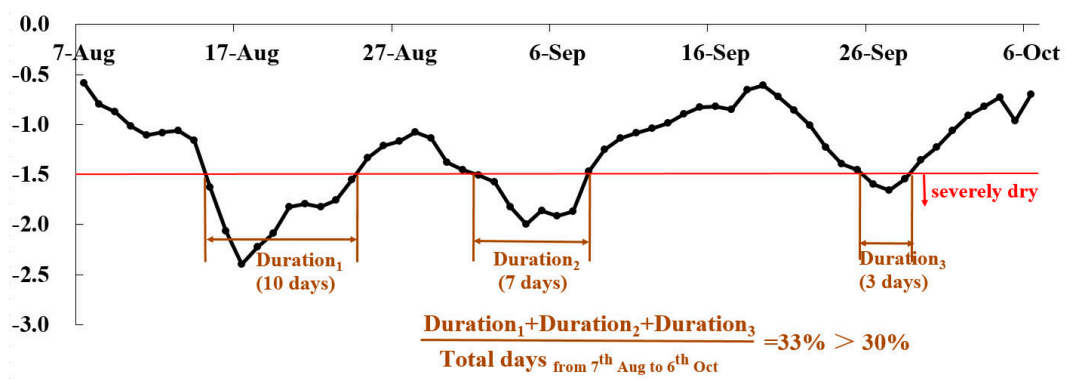

Figure 2. The 2006 summer drought event used as an example of assigning a grade to the entire drought process.

To analyze the characteristics of different drought and wetter phases, we divided the recognized processes into three parts: occurrence, persistence, and recovery. When the SPI1 series was first below -1.50 (above +1.50), we defined the period prior to this date as the occurrence phase of the drought (wetter) event. Similarly, when the series was eventually below -1.50 (above +1.50 ), we defined the period after this date as the recovery phase. We treated the remaining central part as the persistence phase.

\subsection{Calculating Water-Vapor-Related Variables}

Water-vapor-related variables were calculated based on R2 data products. Because the daily specific humidity was not obtained directly from the model outputs in R2, we calculated these values by using daily relative humidity and daily air temperature subsets following the Clausius-Clapeyron relation. The daily $\mathrm{u}$ and $\mathrm{v}$ components of the wind subsets over a range of 1000-300 hPa were used to calculate the daily meridional (zonal) WVT and water vapor flux divergence $(D(Q))$ of each pressure level. Accordingly, the vertically integrated $\mathrm{D}(Q)$ and the meridional (zonal) component of the vertically integrated WVT flux were calculated at the daily timescale. Furthermore, the timescale of the anomalous WVT needs to match that of SPI1, because SPI1 describes the ranking of the past 1-month precipitation amount on historical records. However, this 31-day WVT led to a high risk of excessively attenuating the synoptic signal. Instead, the 21-day mean method was adopted. The ERA-Interim data products were also used for comparison of spatial resolution in the WVT calculation. Their timescales were first transformed from $6 \mathrm{~h}$ to 1 day by using a simple time-averaged method. Subsequently, we used the data-processing methods of $\mathrm{R} 2$ for these values.

\subsection{Applying Standardized Anomalies to Identify Anomalous Features}

According to previous studies on WVT issues such as droughts, anomalous features can be identified by using three main methods: (1) compositing the elements of drought and wetter events [20]; (2) calculating the anomalies with respect to the climatology [21]; and (3) decomposing variables into 
their mean component and transient eddies [22]. In this study, to evaluate the water-vapor-related anomalies objectively, we selected the method of standardized anomalies (SA), which was first used to effectively identify high-impact weather events $[23,24]$ and has significant values in identifying extreme weather events [25-27]. The SA of any meteorological variable is defined by Hart and Grumm [24] to objectively rank synoptic-scale events. It can be described as

$$
S A=\frac{X-\mu}{\sigma}
$$

where $S A$ is the standardized anomaly, $X$ represents the value of a meteorological variable at each grid point, and $\mu$ and $\sigma$ are the mean value and the standard deviation for the grid point, respectively.

$X$ is a variable defined as the 21-day running mean value centered on the day being investigated. Accordingly, both $\mu$ and $\sigma$ for the climatological period (1979-2014) are calculated based on this value. In this study, $X$ represents the meridional (zonal) WVT flux, meridional (zonal) vertically integrated WVT flux, and vertically integrated $\mathrm{D}(Q)$. These water-vapor-related variables were originally averaged daily because they were calculated based on daily wind and specific humidity from the R2 data, as described in Section 2.2. However, after being processed into 21-day running mean variables, $X$ represent the 21-day running mean water-vapor-related variables.

\section{Results}

\subsection{Captured Drought and Wetter Events}

As shown in Figure 3, over the 36-year period from 1979 to 2014, eight drought processes and ten wetter processes occurred with severe or extreme grades. Among these processes, the severity of both the 1992 and the 2011 processes was extremely dry, whereas that of the 1998 process was extremely wet. For convenience, we treated extreme drought and wetter processes as severe processes. Despite various durations and severity, the drought and wetter processes were both evenly distributed throughout the summer and early fall periods.

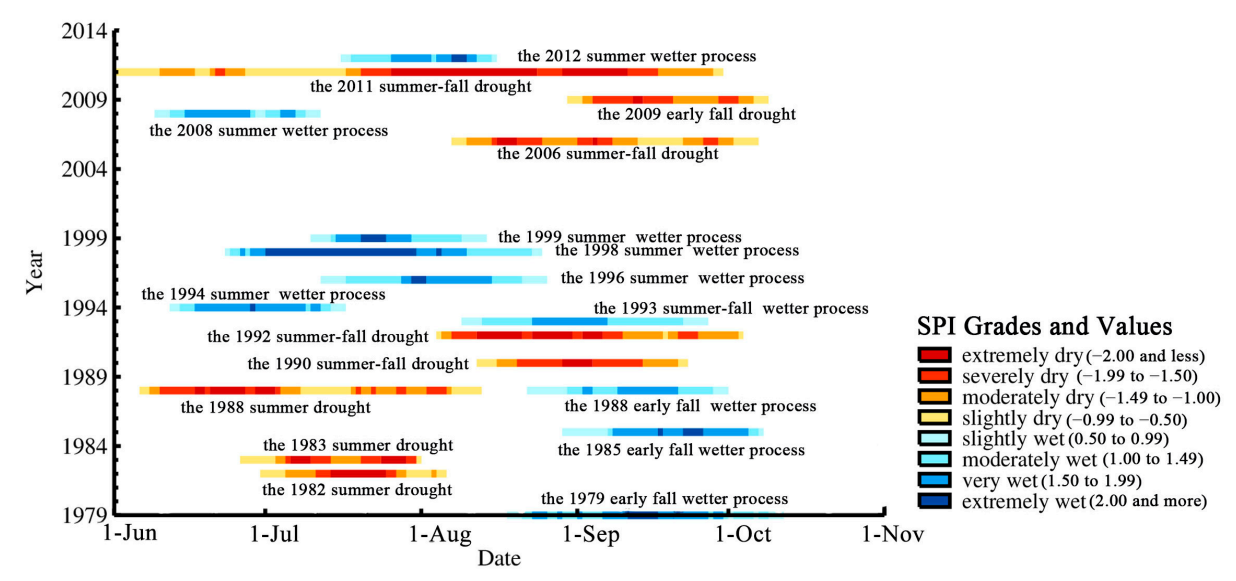

Figure 3. Temporal evolution of identified severe summer and early fall drought and wetter processes from 1979 to 2014 in Southwest China (SWC) based on one-month SPI (SPI1).

\subsection{Spatial Distribution of SPI1 and Vertically Integrated Water Vapor Flux Divergence}

Negative gridded SPI1 covered almost the entire region except for a small northern area (Figure 4a), while the extremely negative values centered on $22.5^{\circ} \mathrm{N}, 105^{\circ} \mathrm{E}$. The drought severity deepened gradually from north to south. Figure $4 \mathrm{~b}$ shows that the slightly positive vertically integrated $\mathrm{D}(Q)$ covered almost the entire region. Two positive SA centers occurred in the southern part, whereas a negative center existed in the northern region. This configuration of vertically integrated $D(Q)$ anomalies is similar to that of gridded SPI1. 
(a) gridded SPI1

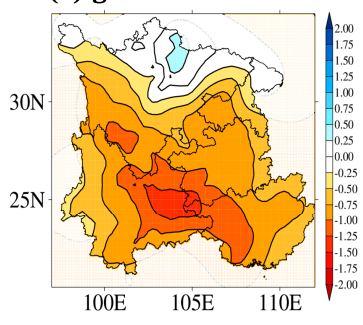

(b) vertically integrated $\mathrm{D}(Q)$

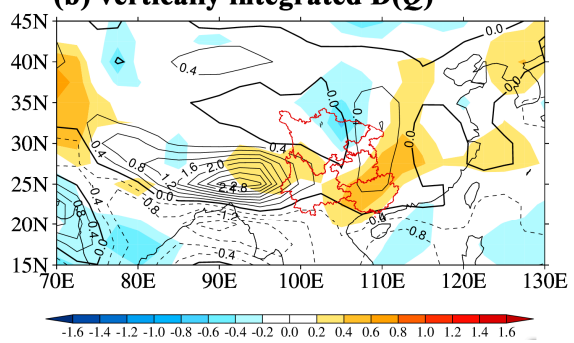

Figure 4. Composite of: (a) gridded SPI1; and (b) vertically integrated water vapor flux divergence $(\mathrm{D}(Q)$; contours) and its standardized anomalies (SA; shadows) during drought processes in Southwest China (SWC). The unit of $\mathrm{D}(Q)$ is $10^{-4} \cdot \mathrm{kg} \cdot \mathrm{s}^{-1} \cdot \mathrm{m}^{-2}$.

\subsection{Anomalous Features of Water Vapor Transport during Drought Processes}

\subsubsection{Geographical Features of Vertically Integrated Water Vapor Transport}

As shown in Figure 5a,e, the cross-equatorial flow divided into two flows at approximately $17.5^{\circ} \mathrm{N}, 97.5^{\circ} \mathrm{E}$ during the summer and early fall drought processes. One branch moved directly to the north. The other branch moved easterly to the SCS, where it began to shift toward the north. In terms of the vertically integrated WVT, the anomalous areas, marked in the figure by black circles, are closely related to the Somalia region and the IndoChina-Peninsula.
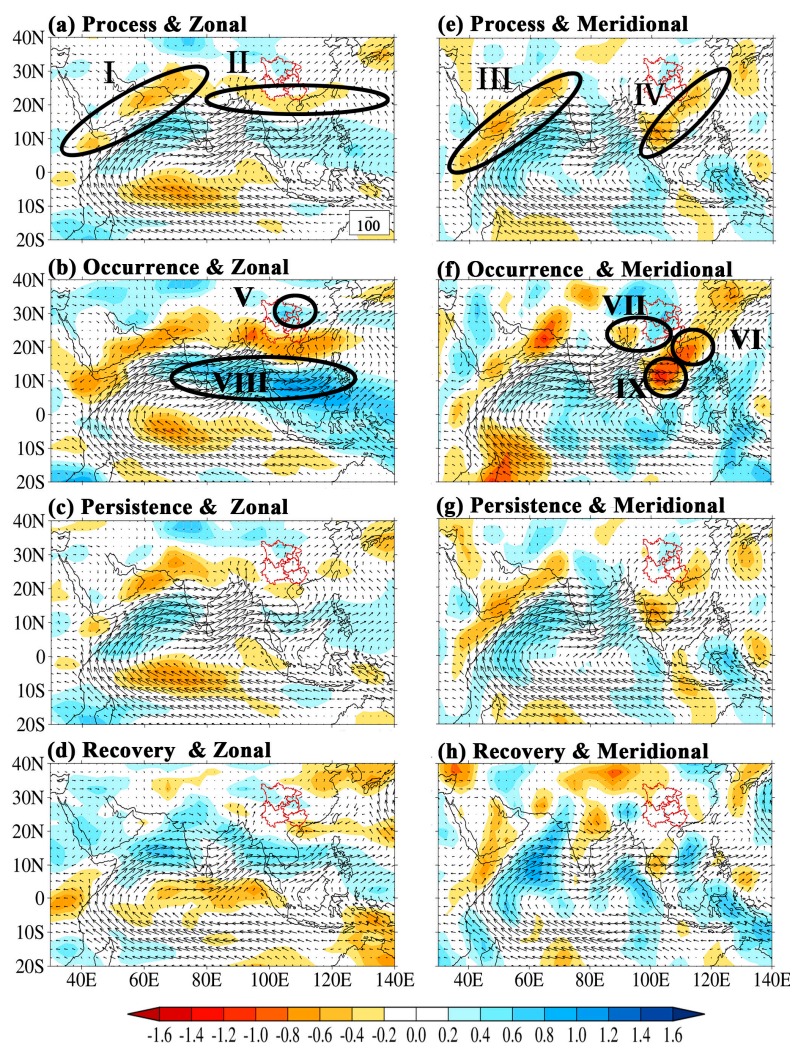

Figure 5. Composites of vertically integrated water vapor transport (WVT) and their zonal standardized anomalies (SA) for drought: (a) processes; (b) occurrence; (c) persistence; and (d) recovery phases; and $(\mathbf{e}-\mathbf{h})$ the same as $(\mathbf{a}-\mathbf{d})$, respectively, but for meridional SA. Vectors represent vertically integrated WVT, whereas shadows represent zonal or meridional SA. The unit of WVT is $\mathrm{kg} \cdot \mathrm{m}^{-1} \cdot \mathrm{s}^{-1}$. The northward and eastward direction of transport is positive. 
As shown in Areas I and II in Figure 5, zonally less-than-normal African-Asian continental WVT anomalies originating from Somalia, are referred to as the Somali channel in our study. This feature has not been explored extensively in previous studies. In addition to zonal anomalies, the Somali channel also shows meridional anomalies in northward WVT (Area III in Figure 5). The other channel appears in the southern part of the IndoChina-Peninsula, where WVT from the BOB moves to the east of the SCS instead of directly entering SWC. Thus, the IndoChina-Peninsula channel represents the less-than-normal meridional component of the cross-equatorial flow into SWC along the IndoChina-Peninsula (Area IV in Figure 5). This finding is consistent with those in previous studies such as the negative meridional WVT in the IndoChina-Peninsula during the 2006 summer drought [3]. Moreover, WVT anomalies during drought occurrence were intensified and concentrated, whereas those during the other phases were weak and scattered. For example, the Somali channel was continuous and the strongest at the drought occurrence (Figure 5b), after which they gradually became scattered and even disappeared. Additionally, the intensified zonal anomalies (Area VIII in Figure 5), are closely related to the IndoChina-Peninsula channel (Area IX in Figure 5). These findings indicate that the intensified zonal southwest monsoon contributed to the maintenance of the meridionally less-than-normal WVT of the IndoChina-Peninsula channel.

\subsubsection{Vertical Features of Water Vapor Transport at Boundaries of SWC}

Because the WVT anomalies at the boundaries of SWC have direct effects on the evolution of drought processes, the vertical features of these anomalies at the boundaries were investigated. As shown in Figure 6a, two meridionally less-than-normal WVT anomalies were located at 850-1000 hPa over $85.0^{\circ} \mathrm{E}-95.0^{\circ} \mathrm{E}$ and $600-1000 \mathrm{hPa}$ over $100.0^{\circ} \mathrm{E}-120.0^{\circ} \mathrm{E}$. The meridionally more-than-normal transport was located at $300-600 \mathrm{hPa}$ over $92.5^{\circ} \mathrm{E}-102.5^{\circ} \mathrm{E}$. This anomalous configuration is associated with geographically meridional WVT anomalies (Figure 5f). However, while turning to the recovery phase (Figure 6e), the two weak transport centers disappeared, and the strong transport center at the upper level became weak and moved from $97.5^{\circ} \mathrm{E}$ to $110^{\circ} \mathrm{E}$. Similar temporal-evolution features occurred along $97.5^{\circ} \mathrm{E}$ and $110^{\circ} \mathrm{E}$.
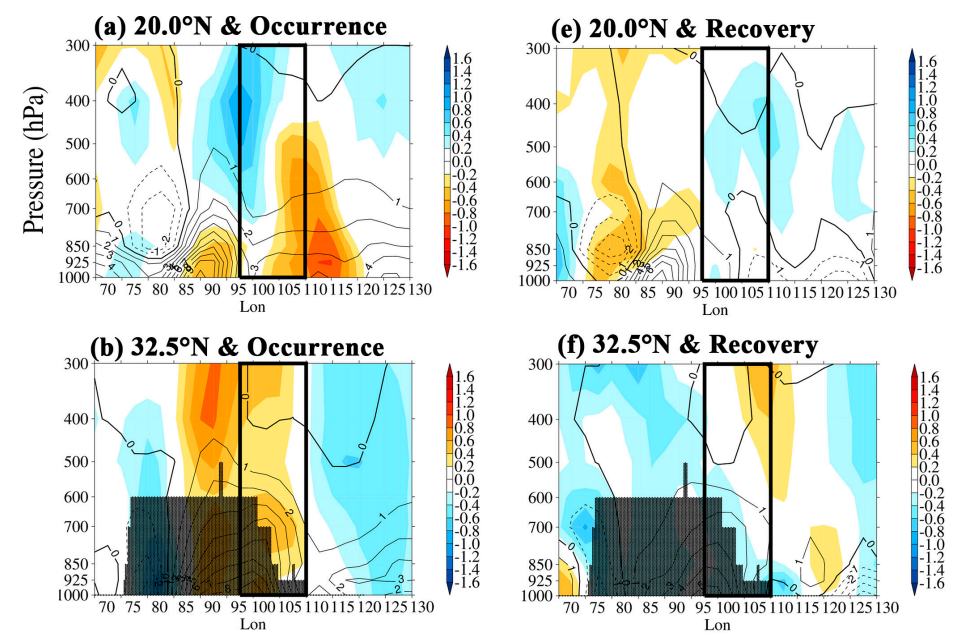

(c) $97.5^{\circ} \mathrm{E} \&$ Occurrence
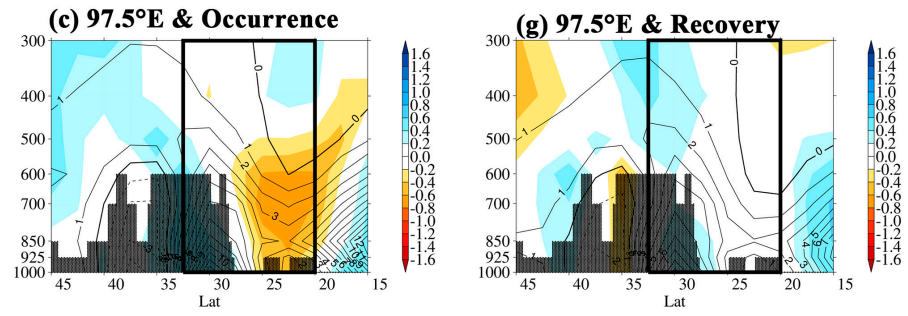

Figure 6. Cont. 
(d) $110.0^{\circ} \mathrm{E} \&$ Occurrence

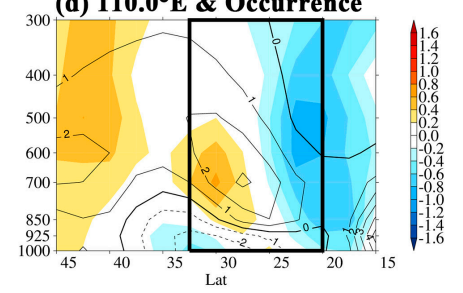

(h) $110.0^{\circ} \mathbf{E} \&$ Recovery

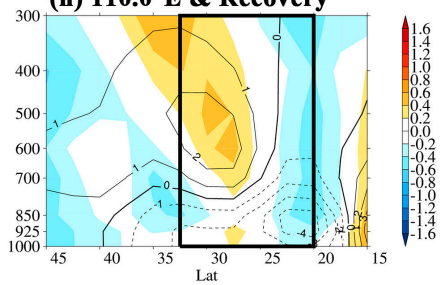

Figure 6. Vertical cross-sections of composited meridional or zonal water vapor transport (WVT) at drought: (a-d) occurrence; and (e-h) recovery at boundaries of Southwest China (SWC). The contours represent WVT, for which the unit is $10^{-1} \cdot \mathrm{kg} \cdot \mathrm{m}^{-1} \cdot \mathrm{s}^{-1} \cdot \mathrm{hPa}^{-1}$. Standardized anomalies (SA) are shown by shadows, whereas warm and cold colors indicate inflow and outflow, respectively. The bold black box indicates the area over SWC. The black shadow areas in $(\mathbf{b}, \mathbf{c}, \mathbf{f}, \mathbf{g})$ represent the Qinghai-Tibet Plateau.

\subsubsection{Comparison with Characteristics of Wetter Processes}

Whether some drought-related anomalies are distinguished from those wet-related anomalies is another issue. We also examined water-vapor-related anomalies during wetter processes and their phases. As shown in Figure 7, almost the entire region showed positive gridded SPI1. An extremely positive center was located at $25^{\circ} \mathrm{N}, 110^{\circ} \mathrm{E}$. A positive SPI1 gradually increased from northwest to southeast, and this spatial distribution is similar to that shown in Figure 4a. This comparison of spatial distribution also reveals that the southern part of SWC is an important region for determining whether the entire SWC will experience droughts. The configuration of positive and negative anomalies of the vertically integrated $\mathrm{D}(Q)$ was similar to that in Figure $4 \mathrm{~b}$ but showed reverse signals.

\section{(a) gridded SPI1}

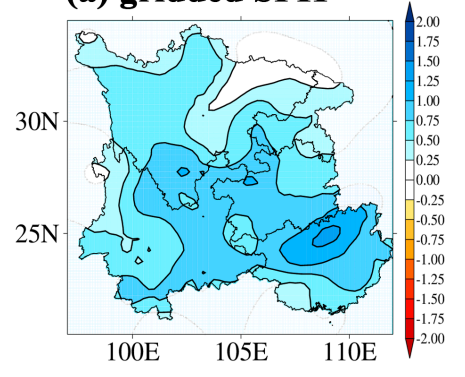

(b) vertically integrated $\mathrm{D}(Q)$

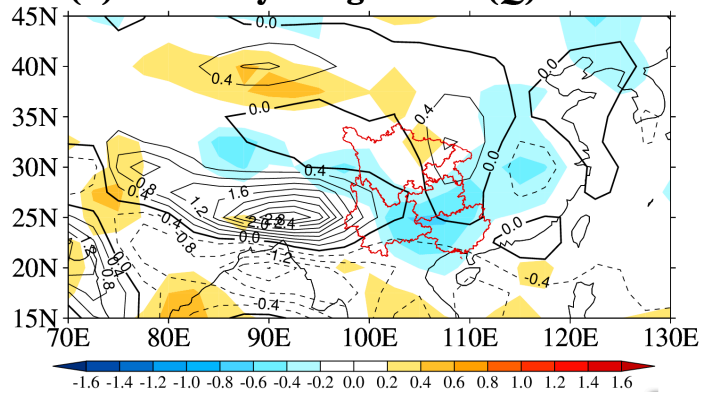

Figure 7. Composite of: (a) gridded SPI1; and (b) vertically integrated water vapor flux divergence $(\mathrm{D}(Q)$; contours) and its standardized anomalies (SA; shadows) during wetter processes in Southwest China (SWC). The unit of $\mathrm{D}(Q)$ is $10^{-4} \cdot \mathrm{kg} \cdot \mathrm{s}^{-1} \cdot \mathrm{m}^{-2}$.

Considering the representativeness of the different phases for WVT anomalies, the wet occurrence and recovery were selected for comparison. As shown in Figure 8, the anomalies in Area IV and $\mathrm{V}$ had reverse signals of those in Figure $5 \mathrm{~b}$,f. This indicates that the WVT anomalies of the Somali and IndoChina-Peninsula channels are also distinguishable, in terms of occurrence phases of drought and wetter processes. Furthermore, two valuable characteristics of WVT anomalies were found at the synoptic scale. As shown in Area II in Figure 8, one branch of the Somali channel entered SWC from its southwest corner, which indicates sign reversal from that of Area VII in Figure 5. Moreover, by combining Area I and Area III in Figure 8, negative zonal WVT anomalies and positive meridional WVT anomalies can be found. This WVT branch came from the SCS but originated from the cross-equator jets and southwest summer monsoon. This analysis indicates that both southwest and northeast parts are key regions of WVT anomalies. Compared with those during wet occurrence, the configurations of SA during wet recovery disappeared or became weaker. 
(a) Occurrence \& Zonal

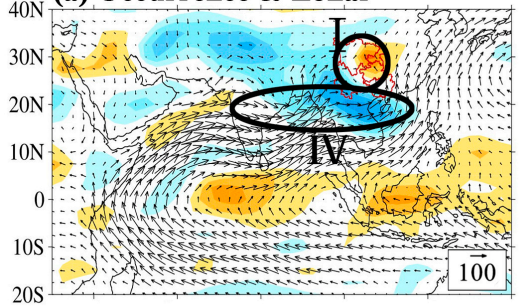

(b) Recovery \& Zonal
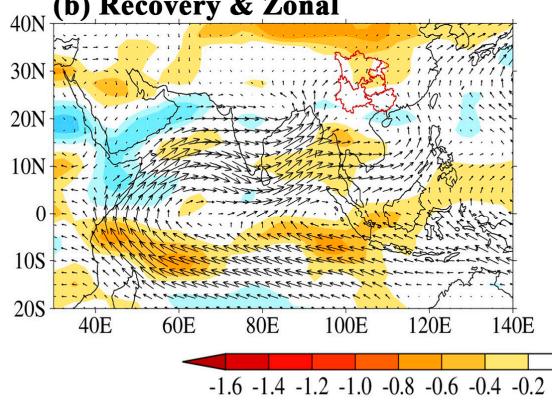

(c) Occurrence \& Meridional

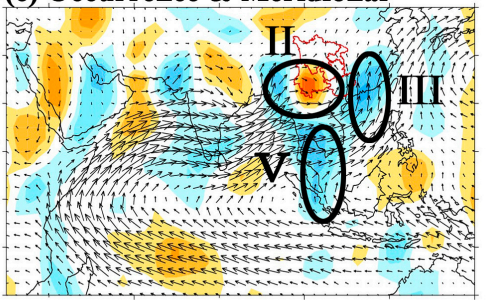

(d) Recovery \& Meridional

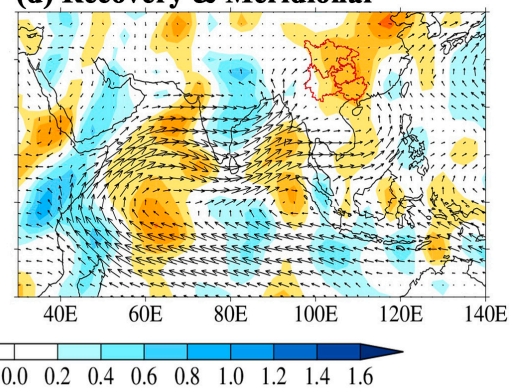

Figure 8. Composites of vertically integrated water vapor transport (WVT) and corresponding zonal standardized anomalies (SA) for wetter: (a) occurrence; and (b) recovery phases; and (c,d) the same as $(\mathbf{a}, \mathbf{b})$, respectively, but for meridional SA. Vectors represent WVT, whereas shadows represent SA. The unit of WVT is $\mathrm{kg} \cdot \mathrm{m}^{-1} \cdot \mathrm{s}^{-1}$. The northward and eastward directions of transport are positive.

In addition to the geographical WVT anomalies, we studied the anomalous signals of the vertical cross-sections at different boundaries (Figure 9). In terms of wet occurrence, except for the $32.5^{\circ} \mathrm{N}$ boundary, anomalous features along $20.0^{\circ} \mathrm{N}, 97.5^{\circ} \mathrm{E}$, and $110.0^{\circ} \mathrm{E}$ were distinguishable and showed sign reversal from those of drought occurrence. These anomalies matched well with Areas II, III, and V in Figure 8. For wet recovery, however, WVT anomalies at $20.0^{\circ} \mathrm{N}$ in the wetter process showed sign reversal from that of drought, whereas WVT anomalies at the other boundaries were implicit and scattered.

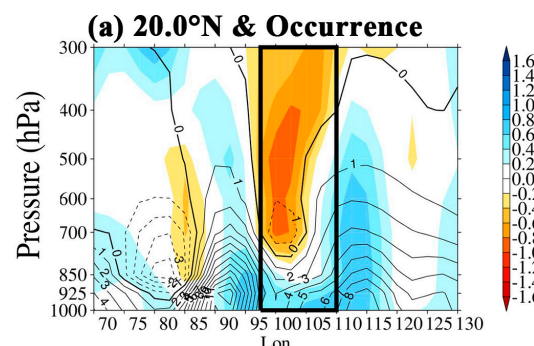

(e) $20.0^{\circ} \mathrm{N} \&$ Recovery

(b) $32.5^{\circ} \mathbf{N} \&$ Occurrence
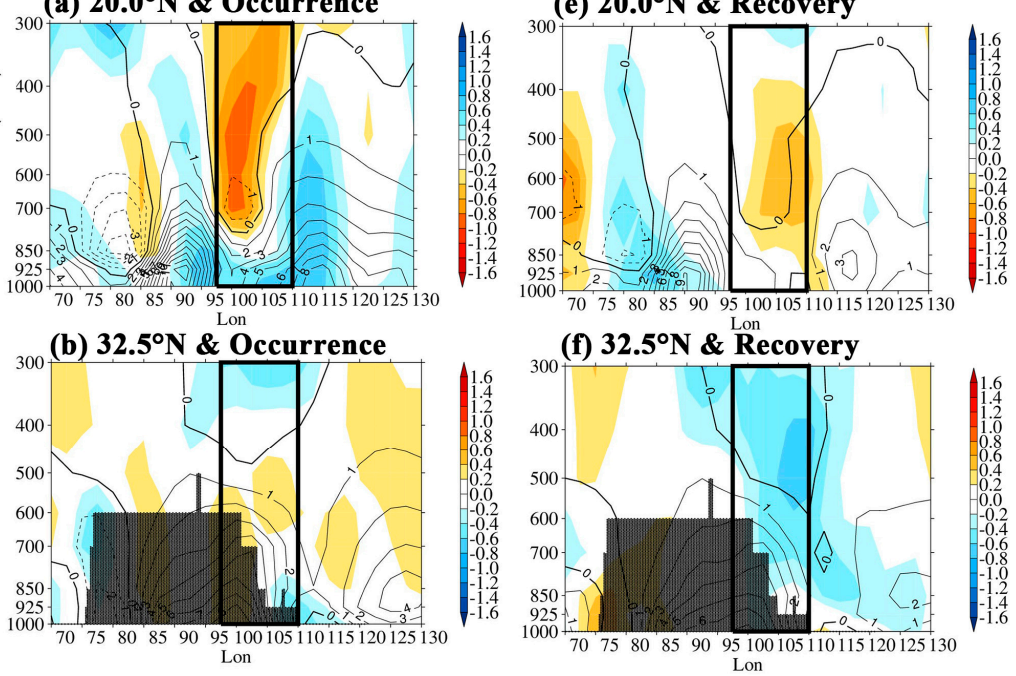

(f) $32.5^{\circ} \mathrm{N} \&$ Recovery

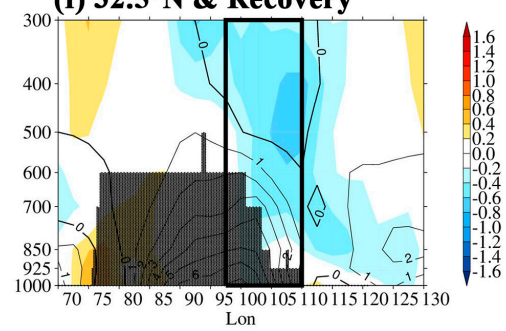

Figure 9. Cont. 
(c) $97.5^{\circ} \mathrm{E} \&$ Occurrence

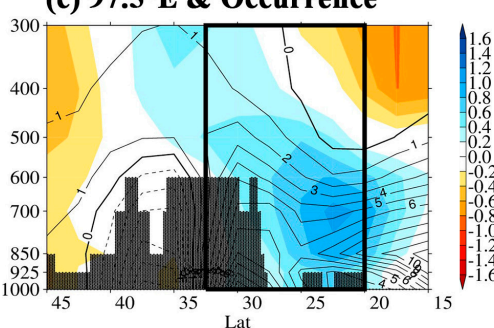

(d) $110.0^{\circ} \mathrm{E} \&$ Occurrence

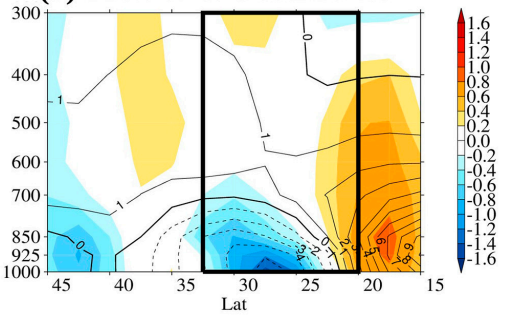

(g) $97.5^{\circ} \mathbf{E} \&$ Recovery

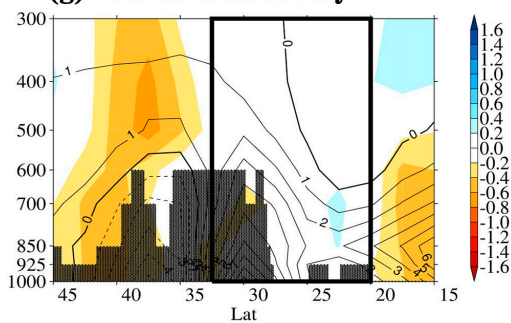

(h) $110.0^{\circ}$ E \& Recovery

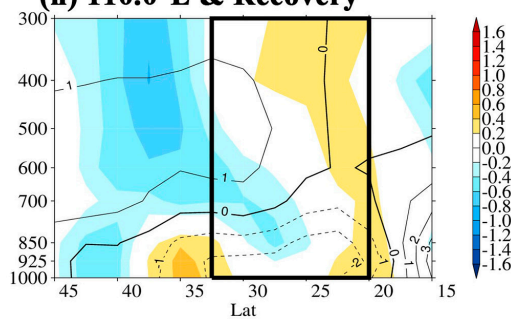

Figure 9. Vertical cross-sections of composite meridional or zonal water vapor transport (WVT) for wetter: (a-d) occurrence; and (e-h) recovery at boundaries of Southwest China (SWC). Contours represent WVT, for which the unit is $10^{-1} \mathrm{~kg} \cdot \mathrm{m}^{-1} \cdot \mathrm{s}^{-1} \cdot \mathrm{hPa}{ }^{-1}$. Standardized anomalies (SA) are shown by shadows, whereas warm and cold colors indicate inflow and outflow, respectively. The bold black box indicates the area over SWC. The black shadow areas in $(\mathbf{b}, \mathbf{c}, \mathbf{f}, \mathbf{g})$ represent the Qinghai-Tibet Plateau.

\subsubsection{Relationship between Geographical Water Vapor Transport Anomalies and Drought Processes}

Geographical WVT anomalies (Figure 5a,e) are closely related to the development of severe summer and early fall droughts in SWC. To study the correlation between these anomalies and drought processes, indices were built to quantify the geographical WVT anomalies. Two geographically anomalous WVT channels were described by extracting grid points, which were selected with composite SA below -0.2 in Area I, II, and IV in Figure 5. In Figure 10, green circles represent the Somali channel, and blue blocks refer to the IndoChina-Peninsula channel. The associated indices of the WVT anomalies were calculated by averaging all of the chosen grid-point SA. The indices of the IndoChina-Peninsula and Somali channels were calculated by using meridional and zonal SA, respectively.

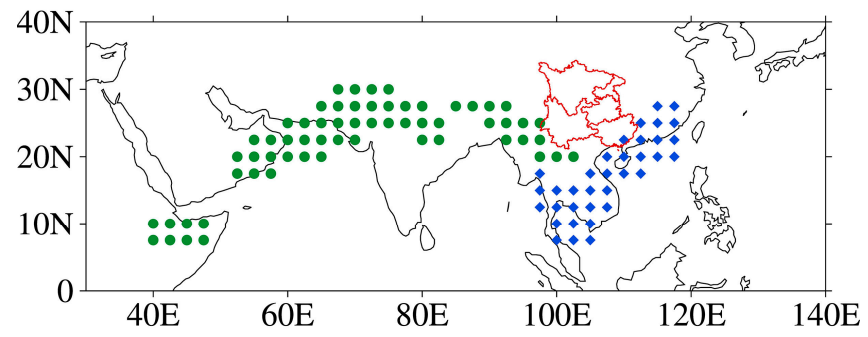

Figure 10. Example of structuring drought-related indices based on geographical anomalies (Areas I, II, and IV in Figure 5) during composite drought processes. The extracted grid points represent selected channels for index definition. Green circles and blue blocks represent the zonally less-than-normal WVT from Somalia and the meridionally less-than-normal WVT from the IndoChina-Peninsula, respectively.

As shown in Table 2 and Figure 11, the index of the IndoChina-Peninsula channel had significant synchronous correlation with SPI1 during seven drought processes, whereas the index of the Somali channel had significant synchronous correlation during only four drought processes. The synchronous correlation coefficient of the Somali channel and the 1982 summer drought process was 0.83 , whereas 
that of the IndoChina-Peninsula channel and the 1992 summer-fall drought process was 0.82 . During the 2009 early fall drought and the 2011 summer-fall drought processes, they were both significantly related to these two anomalous WVT channels despite the negative synchronous correlations. Moreover, these two anomalous WVT channels had high synchronous correlation with the development of wetter processes.

Table 2. Synchronous correlation coefficients between indices of geographical water vapor transport (WVT) anomalies and SPI1 during severe drought and wetter processes. The bold values indicate those exceeding the $95 \%$ confidence level by Student's $t$ test.

\begin{tabular}{cccccc}
\hline $\begin{array}{c}\text { Drought } \\
\text { Years }\end{array}$ & $\begin{array}{c}\text { Index of } \\
\text { Somali-Channel }\end{array}$ & $\begin{array}{c}\text { Index of IndoChina- } \\
\text { Peninsula-Channel }\end{array}$ & $\begin{array}{c}\text { Wetter } \\
\text { Years }\end{array}$ & $\begin{array}{c}\text { Index of } \\
\text { Somali-Channel }\end{array}$ & $\begin{array}{c}\text { Index of IndoChina- } \\
\text { Peninsula-Channel }\end{array}$ \\
\hline 1982 & $\mathbf{0 . 8 3}$ & -0.2 & 1979 & $-\mathbf{0 . 4 3}$ & $\mathbf{0 . 6 1}$ \\
1983 & 0 & $-\mathbf{0 . 5 7}$ & 1985 & $-\mathbf{0 . 5}$ & $-\mathbf{0 . 6 3}$ \\
1988 & 0.15 & $\mathbf{0 . 3 5}$ & 1988 & $-\mathbf{0 . 4 2}$ & -0.17 \\
1990 & $\mathbf{0 . 5 4}$ & $\mathbf{0 . 3 9}$ & 1993 & 0 & $-\mathbf{0 . 5 3}$ \\
2006 & -0.19 & $-\mathbf{0 . 2 8}$ & 1994 & $-\mathbf{0 . 6 1}$ & $-\mathbf{0 . 6 8}$ \\
2009 & $\mathbf{0 . 4}$ & $\mathbf{- 0 . 4 9}$ & 1996 & $\mathbf{0 . 7 5}$ & $-\mathbf{0 . 7 4}$ \\
1992 & 0.16 & $\mathbf{0 . 8 2}$ & 1998 & $-\mathbf{0 . 4 9}$ & $-\mathbf{0 . 7 4}$ \\
2011 & $\mathbf{0 . 4 1}$ & $\mathbf{- 0 . 2 6}$ & 1999 & -0.13 & -0.05 \\
& & & 2008 & -0.12 & $-\mathbf{0 . 6 7}$ \\
& & & 2012 & $\mathbf{0 . 6}$ & $-\mathbf{0 . 2 6}$ \\
\hline
\end{tabular}
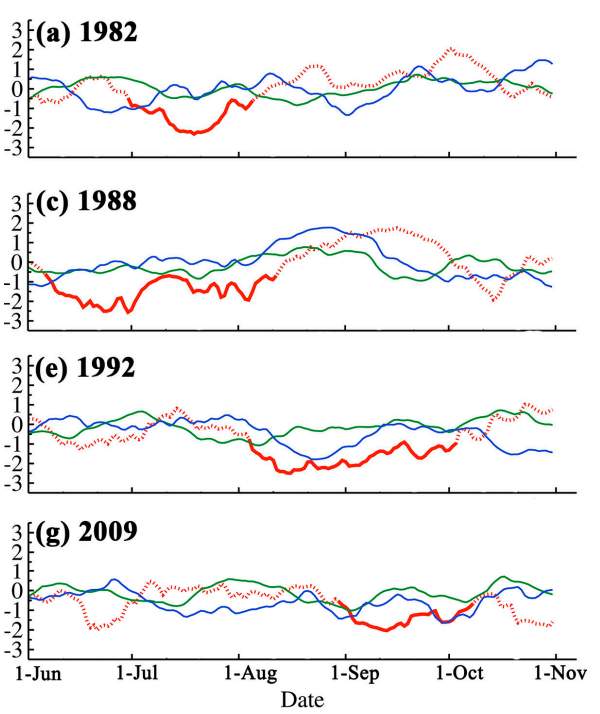

—Index of IndoChina -Peninsula channel — Index of Somali channel — SPI1

Figure 11. Temporal evolution of SPI1 and indices of identified anomalous channels during severe drought processes. Dotted red curves refer to the SPI1 processes from 1 June to 31 October, whereas solid red curves represent drought processes.

Although these two geographically anomalous WVT channels have relatively significant synchronous correlations with these drought and wetter processes, the impact of these drought-related WVT anomalies on the development of drought and wetter events is likely to be lagging. The development of the 1990 summer-fall drought process is quite similar to those two indices but is lagging (Figure 11d). Essentially, it is feasible to investigate lagged correlations between these two indices and the drought processes. For example, if the lead time is 10 days and the drought process is from 21 November 1988, to 9 January 1989, the correlation coefficient between the anomalous WVT indices from 11 November 1988, to 30 December 1989, and the SPI1 from 21 November 1988, to 9 January, 1989 can be calculated. 
In terms of the Somali channel and the 1990 drought process, the lagged correlation coefficient reached the peak for the first time when the lead time was the eighth day (Figure 12a), and these significantly positive correlations persisted for several days. When the lead time was approximately 25 days, the index of the IndoChina-Peninsula channel originally related to drought had the highest correlation coefficients with most of the wetter processes (Figure 12d). Generally, the IndoChina-Peninsula channel performed better in lagged correlations with the drought and wetter processes than the Somali channel.

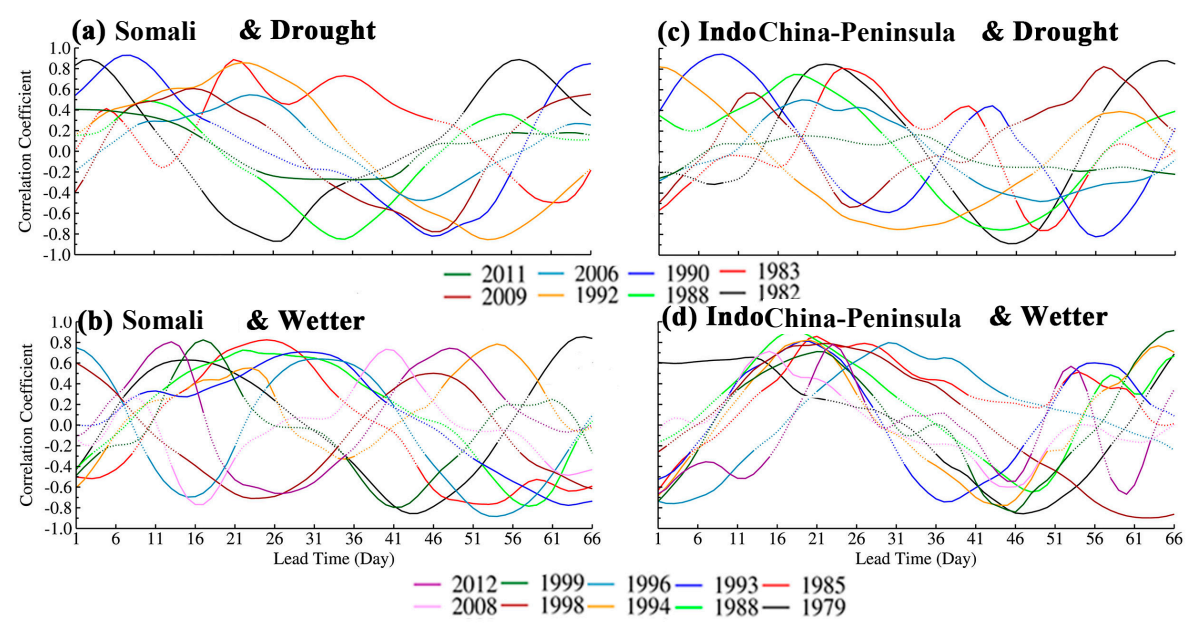

Figure 12. Evolution of lagged correlation coefficients between two indices of geographical water vapor transport (WVT) anomalies and SPI1 during: $(\mathbf{a}, \mathbf{c})$ drought; and $(\mathbf{b}, \mathbf{d})$ wetter processes. Solid and dotted line segments correspond to passing and failing Student's t test, respectively.

\section{Discussion}

The study focuses on the geographical and vertical features of WVT anomalies associated with drought processes and their key phases. The WVT anomalies at drought occurrences (Figure $5 b, f$ and Figure 6a-d) were found to be more intense and more concentrated than those at drought recovery (Figure 5d,h and Figure 6e-h). The reasons for this phenomenon may lie in the method described in Section 2.4, which demonstrates that standardized anomalies are calculated based on 21-day running mean variables. Because the occurrence of meteorological drought depends mainly on long-term precipitation deficits, the 21-day running mean method is rational. However, meteorological drought recovery corresponds to heavier precipitation persisting for several days, associated with shorter-term timescales of circulation patterns. Therefore, it is expected that drought recovery is calculated on the basis of shorter duration running mean variables. To verify this assumption, a sensitivity experiment was designed with running mean WVT anomalies of different durations (Figure 13). When the running mean duration ranges 1-21 days, the WVT anomalies tended to be gradually stronger, no matter it is during drought occurrence or drought recovery. Moreover, the spatial distribution of anomalous WVT channels did not change. The experiment results were different from the original assumption, which means that WVT anomalies at drought recovery were not intensified based on the running mean WVT anomalies of shorter duration. The reason is that, when the one-day-mean method is used, synoptic-scale WVT anomalies have been eliminated by using the composite method, resulting in weak anomalies. In comparison, the 21-day mean results indicated relatively evident and steady WVT anomalies. The 21-day mean method used in our study indicated that the temporal scale of WVT anomalies tended to be in the extended range scale, which is actually between planetary and synoptic scales. 

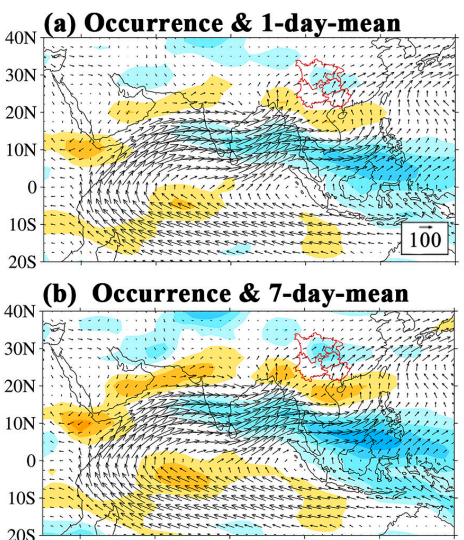

(c) Occurrence \& 15-day-mean

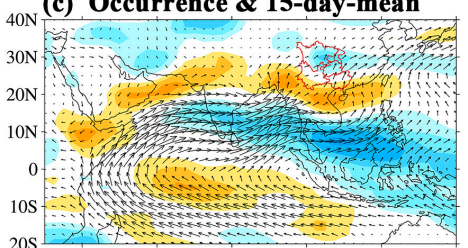

(d) Occurrence \& 21-day-mean

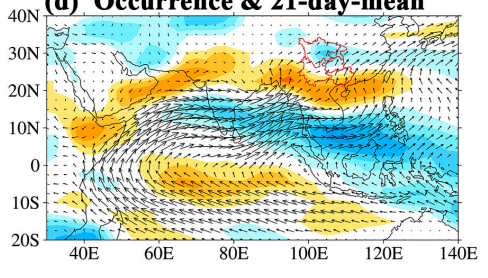

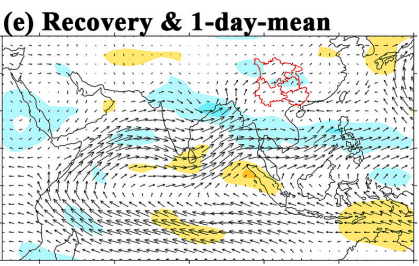

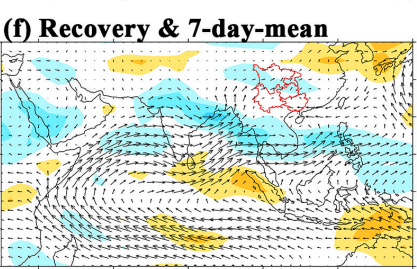

(g) Recovery \& 15-day-mean

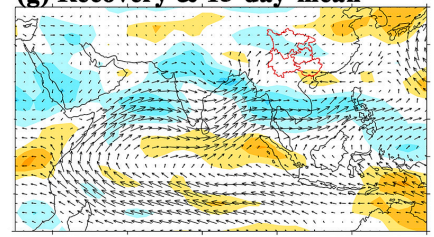

(h) Recovery \& 21-day-mean

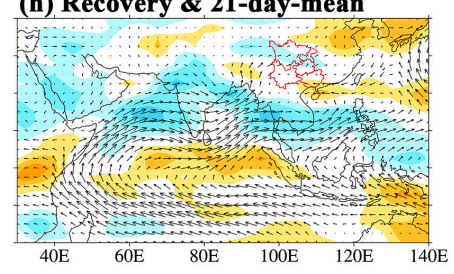

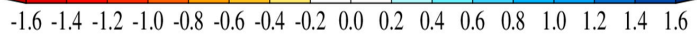

Figure 13. Composite of vertically integrated water vapor transport (WVT) and different duration running mean zonal standardized anomalies (SA) for drought: (a-d) occurrence; and (e-h) recovery phases. Vectors represent WVT, whereas shadows represent SA. The unit of WVT is $\mathrm{kg} \cdot \mathrm{m}^{-1} \cdot \mathrm{s}^{-1}$. The eastern direction of transport is positive.

Following Section 2.3, daily data subsets of specific humidity, $\mathrm{u}$ and $\mathrm{v}$ were used for daily WVT computation. The method of 21-day running mean was used for these daily water-vapor-related variables, and the values were centered on the investigated day. Subsequently, we investigated anomalous features by using the SA method. Different from the WVT computation in our study, the water vapor transport can generally be separated into two parts: the stationary and the transient components. The former is calculated by using monthly mean data, whereas the latter is evaluated as departures from individual monthly mean values by using four-time daily averaged data [28]. These two components can be partly responsible for the precipitation anomalies in different regions [22,28]. However, the drought processes identified in our study were described by one-month SPI with a daily running window and correspond to different starting and ending dates. It was difficult to analyze stationary and transient components for months such as June, July, and August. In comparison, the WVT computation used in our study is relatively feasible.

The R2 data products used in our study were taken from a $2.5^{\circ} \times 2.5^{\circ}$ latitude-longitude grid. This scale is relatively coarse for moisture flux computation, which might have induced considerable uncertainties and errors [29]. Therefore, the high-resolution ERA-Interim reanalysis datasets were used for comparison of calculated water-vapor-related anomalies, to examine the impact of the spatial resolution on WVT computation. As shown in Figure 14, the re-examined results based on the ERA-Interim datasets generally indicated consistent features of WVT anomalies. Both vertical distribution and intensities of WVT anomalies at the $20.0^{\circ} \mathrm{N}, 97.5^{\circ} \mathrm{E}$, and $110.0^{\circ} \mathrm{E}$ boundaries from 
ERA-Interim (Figure 14a,c,d) were quite similar to those from R2 (Figure 6a,c,d). In contrast, the WVT anomalies at $32.5^{\circ} \mathrm{N}$ were almost opposite to that in Figure $6 \mathrm{~b}$ ), particularly for the area over the Qinghai-Tibet Plateau. However, the WVT anomalies at the former three boundaries from R2 are valid and valuable, which are closely related to the development of drought processes in SWC. Although the anomalies of the vertically integrated $\mathrm{D}(Q)$ from ERA-Interim (Figure 14g) were more detailed and scattered than those from R2 (Figure 4b), negative anomalies in the southern SWC were consistent with those in Figure $4 \mathrm{~b}$. The geographical WVT anomalies (Figure 14e,f) were also almost identical to those in Areas I-IV in Figure 5. Similar to the ERA-Interim results, these R2 results of coarse spatial resolution can also be acceptable in our study. It should be noted that similar comparison and preliminary conclusions were made by Zhou and Yu [28], although they studied WVT associated with the typical anomalous summer rainfall patterns in China with the datasets from R1 and ERA40.

(a) Occurrence \& $20.0^{\circ} \mathrm{N}$

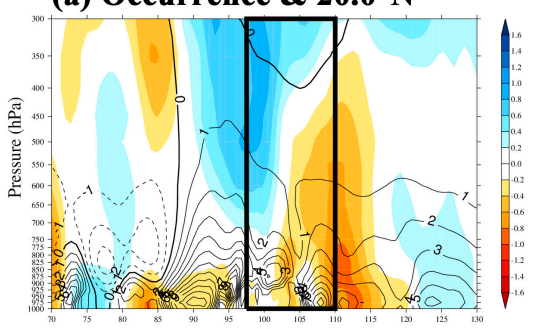

(c) Occurrence \& $97.5^{\circ} \mathrm{N}$

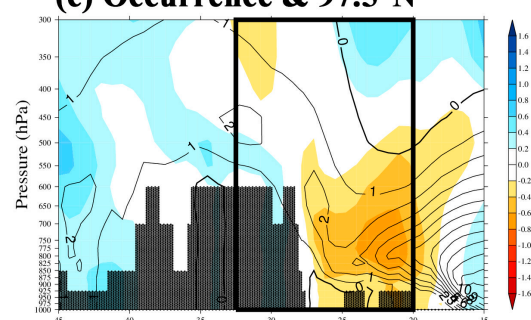

(e) Process \& Zonal
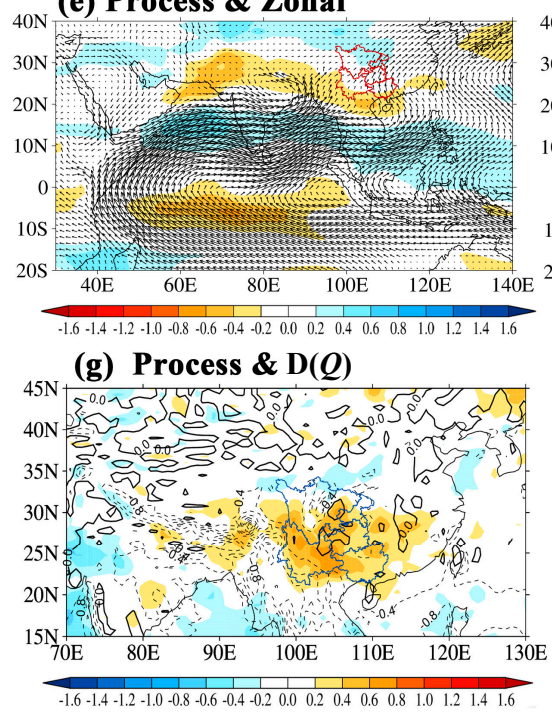

(b) Occurrence \& $32.5^{\circ} \mathrm{N}$

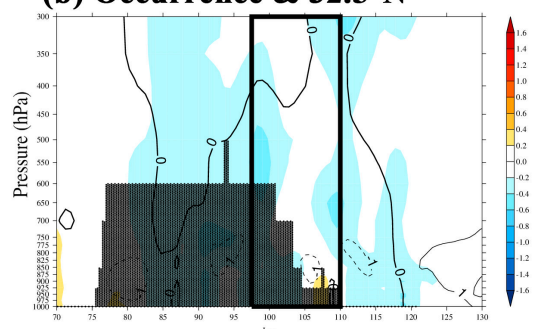

(d) Occurrence \& $110.0^{\circ} \mathrm{N}$

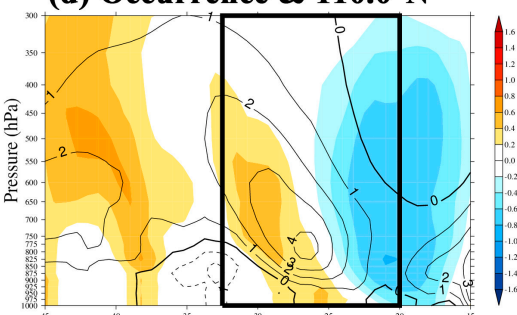

(f) Process \& Meridional

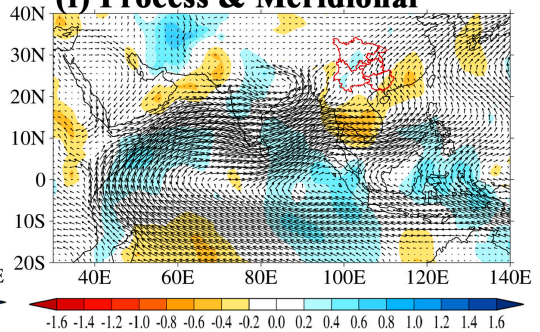

Figure 14. (a-d) Same as Figure 6a-d, respectively, which represent vertical cross-sections of composited meridional or zonal water vapor transport (WVT) for drought occurrences at the boundaries of Southwest China (SWC). (e,f) Same as Figure 5a,e, which are composites of: (e) zonal; and (f) meridional standardized anomalies (SA) of vertically integrated water vapor transport (WVT) for drought processes. (g) Same Figure $4 \mathrm{~b}$, which represents a composite of drought processes for vertically integrated water vapor flux divergence $(\mathrm{D}(Q)$; contours) and its standardized anomalies (SA; shadows) in SWC. The original data source of $(\mathbf{a}-\mathbf{g})$ is ERA-Interim re-analysis datasets. 
WVT anomalies that occurred during summer extreme rainfall events were investigated in previous studies. Compared with the WVT anomalies associated with typical anomalous summer rainfall in China, which were identified by Zhou and Yu [28], two different key points remain in our study. In terms of time scales, Zhou and Yu studied inter-annual variability such as dry and wet years, whereas we examined monthly drought processes and their different phases. Moreover, the definition of the Somali channels involved in these two studies is different. The Somali jet, originating from oceanic areas between $40^{\circ} \mathrm{E}$ and $60^{\circ} \mathrm{E}$, is not related to the typical anomalous summer rainfall in China examined in their study. However, the Somali channel recognized in our study represents zonally less-than-normal African-Asian continental WVT anomalies originating from Somalia. The Somali channel is typically anomalous during the summer and early fall drought processes in SWC.

The synchronous and lagged correlations between geographical WVT anomalies and drought and wetter processes were investigated. These correlations also lasted for several days, such as the approximately common high correlation of the indices of the IndoChina-Peninsula channel at the lead 25th day of wetter processes (Figure 12d). However, due to a natural period of these indices of WVT anomalies, the cycles of indices could have led to false high correlation at relatively long lead times. Even so, the present study indicates potential and relatively steady relationships between WVT anomalies with different lead time and meteorological drought and wetter processes in the short period. The feasible lead time, which makes the aforementioned relationships robust, is fundamental for end water managers to implement timely drought mitigation measures. Besides, how these identified drought-related WVT channels serve seasonal water management is an important issue. To match seasonal timescale, three-month SPI and three-month WVT anomalies should be used to investigate seasonal drought-related channels and appropriate relevant lead time. In addition, it is necessary to explore application of these channels at the appropriate lead day in early seasonal drought warning.

Dynamic and thermodynamic anomalies are also important for the formation and maintenance processes of meteorological drought. For example, when investigating regional atmospheric anomalies responsible for the 2009-2010 severe drought, Lu et al. [30] reported that the warmer-than-normal air temperature is important to the maintenance of the drought under dry atmospheric conditions. The persistent warm temperature makes it hard for the air to become saturated and thus hard for even light rains, which are efficient in mitigating drought, to form. Besides, Feng et al. [6] reported that dry-season droughts in SWC are generally consistent with local anomalous descent in the middle troposphere. Local descent is primarily maintained by the anomalous cold temperature advection processes. Further research will focus on local temperature anomalies and vertical motion, which are important factors in determining whether local water vapor can be transformed to precipitation during the summer and early fall droughts in SWC.

\section{Conclusions}

Water vapor transport (WVT) is an important and direct element for summer and early fall drought processes in SWC. In this study, we investigated WVT anomalies during severe summer and early fall drought processes and their different phases. SA-based indices were built, which enabled us to explore the potential relationship between drought and wetter processes and WVT anomalies. The main results are as follows.

(1) The southern part of SWC is an important region for determining whether the entire SWC will experience summer and early fall drought and wetter processes.

(2) On the basis of the composites of severe drought processes, we identified two drought-related geographical WVT channels with SA below -0.2. The Somali channel is characterized by zonally less-than-normal African-Asian continental WVT anomalies originating from Somalia, whereas the IndoChina-Peninsula channel represents meridionally less-than-normal WVT anomalies originating from the IndoChina-Peninsula. Additionally, WVT anomalies at the south, east, and west boundaries are also essential for the development of drought processes. 
(3) Both geographical and vertical WVT anomalies are intensified and concentrated at drought occurrence, and then weaken and become scattered at drought recovery. Most drought-related WVT anomalies are distinguishable from those of wetter processes.

(4) The IndoChina-Peninsula channel performed better in correlations with these drought and wetter processes than the Somali channel. The lagged correlations between the IndoChina-Peninsula channel and most of the identified wetter processes peaked for the first time before the 25th day of lead time.

Although drought-related WVT anomalies have been discussed in detail in the present study, further research will focus on dynamic and thermodynamic anomalies such as local temperature, associated temperature advection, and vertical motion, which are important factors in exploring drought mechanisms.

Acknowledgments: This work is supported by the Special Public Sector Research Program of Ministry of Water Resources (grant Nos. 201301040 and 201501041), the Fundamental Research Funds for the Central Universities (grant No. 2015B20414), the Program for New Century Excellent Talents in University (grant No. NCET-12-0842), the National Natural Science Foundation of China (grant No. 51579065) and the Natural Science Foundation of Jiangsu Province of China (grant No. BK20131368). We are also extremely grateful for the three anonymous referees. Their detailed and specialized comments helped us revise and think about this issue deeply.

Author Contributions: Zhenchen Liu and Guihua Lu initiated the concept and structured the article. Zhenchen Liu and Hai He processed the meteorological data. Zhenchen Liu prepared Figures 1-10 and wrote the manuscript. Hai He and Zhiyong Wu reviewed the manuscript five times and provided valuable suggestions. Jian He guided the figure drawing and prepared Figures 11-14.

Conflicts of Interest: The authors declare no conflict of interest.

\section{References}

1. Yang, J.; Gong, D.Y.; Wang, W.S.; Hu, M.; Mao, R. Extreme drought event of 2009/2010 over southwestern China. Meteorol. Atmos. Phys. 2012, 115, 173-184. [CrossRef]

2. Wang, L.; Chen, W.; Zhou, W.; Huang, G. Drought in Southwest China: A review. Atmos. Ocean. Sci. Lett. 2015, 8, 339-344.

3. Li, Y.H.; Xu, H.M.; Liu, D. Features of the extremely severe drought in the east of Southwest China and anomalies of atmospheric circulation in summer 2006. Acta Meteorol. Sin. 2011, 25, 176-187. [CrossRef]

4. Yang, S.Q.; Pan, J.H.; Jian, B. Analysis of the extreme heat wave and drought over Sichuan Basin in 2006. J. Southwest Univ. Nat. Sci. Edit. 2008, 30, 133-137. (In Chinese)

5. Li, Z.M.; Chen, J.; Dong, X.N. Comparison analysis for summer heavy drought and its circulation features in 2011/2006 in Chongqing. J. Southwest Univ. Nat. Sci. Ed. 2014, 36, 113-122. (In Chinese)

6. Feng, L.; Li, T.; Yu, W. Cause of severe droughts in Southwest China during 1951-2010. Clim. Dyn. 2014, 43, 2033-2042. [CrossRef]

7. Xu, H.L.; Li, J.P.; Feng, J.; Mao, J.Y. The asymmetric relationship between the winter NAO and the precipitation in Southwest China. Acta Meteorol. Sin. 2012, 70, 1276-1296. (In Chinese)

8. Barriopedro, D.; Gouveia, C.M.; Trigo, R.M.; Wang, L. The 2009/10 drought in China: Possible causes and impacts on vegetation. J. Hydrometeorol. 2012, 13, 1251-1267. [CrossRef]

9. Huang, R.H.; Liu, Y.; Wang, L.; Wang, L. Analyses of the causes of severe drought occurring in Southwest China from the fall of 2009 to the spring of 2010. Chin. J. Atmos. Sci. 2012, 36, 443-457. (In Chinese)

10. Zhang, W.; Jin, F.-F.; Zhao, J.-X.; Qi, L.; Ren, H.-L. The possible influence of a nonconventional El Nino on the severe autumn drought of 2009 in Southwest China. J. Clim. 2013, 26, 8392-8405. [CrossRef]

11. Hu, X.P.; Wang, S.G.; Xu, P.P.; Shang, K.Z. Analysis on causes of continuous drought in Southwest China during 2009-2013. Meteorol. Mon. 2014, 40, 1216-1229.

12. Ai, Y.Z.; Jin, S.H.; Zheng, J.M.; Zhou, H. Asymmetric variation of the circulation over the South China Sea and the Bay of Bengal and its impacts on the serious drought in Southwest China in autumn of 2009. J. Trop. Meteorol. 2012, 28, 594-602. (In Chinese)

13. Liu, X.R.; Yang, Q.; Cheng, B.Y. Study on anomalies of atmospheric circulation and water vapor field of the heavy drought in Sichuan-Chongqing region in midsummer 2006. Meteorol. Mon. 2009, 35, 27-34. 
14. Wang, Z.Y.; Ren, F.M.; Sun, L.; Liu, Y.J.; Wang, P.L.; Tang, J.Y.; Wang, D.Q.; Li, D. Analysis of climate anomaly and causation in summer 2011. Meteorol. Mon. 2012, 38, 448-455.

15. Kanamitsu, M.; Ebisuzaki, W.; Woollen, J.; Yang, S.K.; Hnilo, J.J.; Fiorino, M.; Potter, G.L. NCEP-DOE AMIP-II Reanalysis (R-2). Bull. Am. Meteorol. Soc. 2002, 83, 1631-1643. [CrossRef]

16. Dee, D.P.; Uppala, S.M.; Simmons, A.J.; Berrisford, P.; Poli, P.; Kobayashi, S.; Andrae, U.; Balmaseda, M.A.; Balsamo, G.; Bauer, P.; et al. The ERA-interim reanalysis: Configuration and performance of the data assimilation system. Q. J. R. Meteorol. Soc. 2011, 137, 553-597. [CrossRef]

17. Mckee, T.B.; Doesken, N.J.; Kleist, J. The relationship of drought frequency and duration to time scales. In Proceedings of the 8th Conference on Applied Climatology, Anaheim, CA, USA, 17-22 January 1993; pp. 179-184.

18. Vicente-Serrano, S.M.; Begueria, S.; Lopez-Moreno, J.I. A multiscalar drought index sensitive to global warming: The standardized precipitation evapotranspiration index. J. Clim. 2010, 23, 1696-1718. [CrossRef]

19. World Meteorological Organization. Standardized Precipitation Index User Guide; World Meteorological Organization: Geneva, Switzerland, 2012; Available online: http://www.wamis.org/agm/pubs/SPI/WMO_ 1090_EN.pdf (accessed on 6 February 2017).

20. Mo, K.C.; Paegle, J.N.; Higgins, R.W. Atmospheric processes associated with summer floods and droughts in the central United States. J. Clim. 1997, 10, 3028-3046. [CrossRef]

21. Weaver, S.J.; Ruiz-Barradas, A.; Nigam, S. Pentad evolution of the 1988 drought and 1993 flood over the great plains: An NARR perspective on the atmospheric and terrestrial water balance. J. Clim. 2009, 22, 5366-5384. [CrossRef]

22. Kam, J.; Sheffield, J.; Wood, E.F. A multiscale analysis of drought and pluvial mechanisms for the southeastern United States. J. Geophys. Res. Atmos. 2014, 119, 7348-7367. [CrossRef]

23. Grumm, R.H.; Hart, R. Standardized anomalies applied to significant cold season weather events: Preliminary findings. Weather Forecast. 2001, 16, 736-754. [CrossRef]

24. Hart, R.E.; Grumm, R.H. Using normalized climatological anomalies to rank synoptic-scale events objectively. Mon. Weather Rev. 2001, 129, 2426-2442. [CrossRef]

25. Macias Fauria, M.; Johnson, E.A. Large-scale climatic patterns control large lightning fire occurrence in Canada and Alaska forest regions. J. Geophys. Res. Biogeosci. 2006, 111. [CrossRef]

26. Stuart, N.A.; Grumm, R.H. Using wind anomalies to forecast east coast winter storms. Weather Forecast. 2006, 21, 952-968. [CrossRef]

27. Duan, W.L.; He, B.; Takara, K.; Luo, P.P.; Nover, D.; Yamashiki, Y.; Huang, W.R. Anomalous atmospheric events leading to Kyushu's flash floods, July 11-14, 2012. Nat. Hazards 2014, 73, 1255-1267. [CrossRef]

28. Zhou, T.J.; Yu, R.C. Atmospheric water vapor transport associated with typical anomalous summer rainfall patterns in China. J. Geophys. Res. Atmos. 2005, 110, 12. [CrossRef]

29. Rasmusson, E.M. Hydrological Application of Atmospheric Vapor-Flux Analyses; Report to the 5. Session of WMO Commission for Hydrology; World Meteorological Organization: Geneva, Switzerland, 1977; p. 50.

30. Lu, E.; Luo, Y.; Zhang, R.; Wu, Q.; Liu, L. Regional atmospheric anomalies responsible for the 2009-2010 severe drought in China. J. Geophys. Res. Atmos. 2011, 116. [CrossRef]

(C) 2017 by the authors. Licensee MDPI, Basel, Switzerland. This article is an open access article distributed under the terms and conditions of the Creative Commons Attribution (CC BY) license (http:/ / creativecommons.org/licenses/by/4.0/). 